\title{
The Stages of Student Mathematical Imagination in Solving Mathematical Problems
}

\author{
Teguh Wibowo ${ }^{1}$, Akbar Sutawidjaja ${ }^{1}$, Abdur Rahman As'ari $^{1} \&$ I Made Sulandra ${ }^{1}$ \\ ${ }^{1}$ Department of Mathematics Education, State University of Malang, Indonesia \\ Correspondence: Teguh Wibowo, Department of Mathematics Education, State University of Malang, Indonesia. \\ E-mail: teguhwibowo743@gmail.com
}

Received: February 8, 2017

Accepted: March 12, $2017 \quad$ Online Published: June 27, 2017

doi:10.5539/ies.v10n7p48

URL: https://doi.org/10.5539/ies.v10n7p48

\begin{abstract}
This research is a qualitative study that aimed to describe the stages of students mathematical imagination in solving mathematical problems. There are three kinds of mathematical imagination in solving mathematical problems, namely sensory mathematical imagination, creative mathematical imagination and recreative mathematical imagination. Students can produce one kind of mathematical imagination or other kinds of mathematical imagination. Problem sheet is used as a supporting instrument to find out the stages of students mathematical imagination in solving problems. Three students are used as research subjects in whom students were able to produce their mathematical imagination in solving mathematical problems. The results showed that there are three stages of students mathematical imagination in solving mathematical problems, the first stage is sensory mathematical imagination, the second stage is creative mathematical imagination, and the last stage is recreative mathematical imagination.
\end{abstract}

Keywords: sensory mathematical imagination, creative mathematical imagination, recreative mathematical imagination

\section{Introduction}

Research Nemirovsky and Ferrara (2008) on mathematical imagination shows that mathematical imagination and cognition representative of students involves gestures activity (hand gesture, speech, and other activities of sensory motor) on learning is very important in developing the creativity and innovation of students in solving mathematical problems. Similarly the research that done by Swirski (2010), Samli (2011), Kotsopoulos and Cordy (2009), Van Alphen (2011), they shows these studies support the involvement of imagination in the learning process. Wilke (2010) and Chapman (2008) emphasize the importance of imagination in the learning process and helping students in solving problems.

Imagination is not only the capacity to form the image, but the capacity to think in a certain way. Students should be encouraged to think for themselves by emphasizing their imagination. Imagination can be a main focus in effective learning (Wilke, 2010). In addition, the imagination has been implicated as the key to mathematical creativity in generating and manipulating images (Abrahamson, 2006). In the process of mathematics learning or mathematical problem solving, the ability to imagine has no limits and constraints (Carroll et al., 2010). Egan and Steiner's perspective claim that children between the ages of 5 to 14 years learn best through imagination, because this is a natural mode and strongest when they are involved with knowledge (Van Alphen, 2011). Both perspectives are stressed in order that involve student imagination ability in building knowledge or solve a problem.

There are three types of students' mathematical imagination in solving mathematical problems, namely sensory mathematical imagination, creative mathematical imagination and recreative mathematical imagination (Wibowo \& As'ari, 2014). Sensory mathematical imagination can be seen through the emergence of students perception based stimuli problem in the matter. Creative mathematical imagination manifested through the emergence of relevant or irrelevant ideas in solving the problem. Recreative mathematical imagination manifested through the emergence of generalizing the idea of solving mathematical problem. This study was to determine the stage of students' mathematical imagination in solving mathematical problems. So the aim of this study is to determine stages of students' mathematical imagination in solving mathematical problems. 


\section{Research Methodology}

This study is descriptive qualitative research. Respondents in this study were students of class VIII SMPIT Logaritma Kebumen, Central Java, Indonesia, which amounted to 12 students. Then, we take three students to become our research subject. Subjects were selected based on students ability to solve problems in this study and were able to appear mathematical imagination. To see mathematical imagination that emergence students in solving problem viewed through a visual representation of the student in solving problem (Wibowo \& As'ari, 2014).

The main instrument in this study is the researchers themselves, because researchers who plan, design, implement, collect data, analyze the data, draw conclusions and make a report (Moleong, 2004). The researchers also used the test (problem sheet) and unstructured interviews to collect the data. Problem sheet consists of an item the matter related to solving mathematical problems. Here problem sheet used in this study.

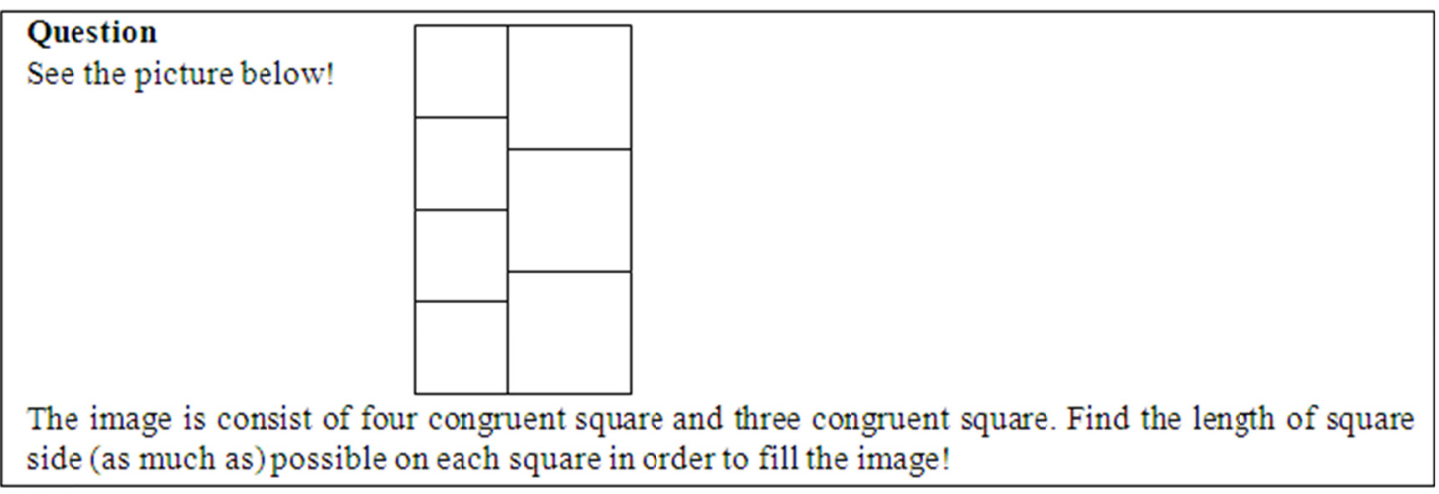

The image is consisted of four congruent squares and three congruent squares. Find the length of square side (as much as) possible on each square in order to fill the image!

The problem in above emphasizes how students can find the length of each square side in order to fill the image. The length of square side here are a couple of numbers that fill the length side of small square and large square. If students find one the length side of square is likely to determine the length of other square side. The results of students visual representation can be seen as how the stages of mathematical imagination in solving the problem. Visualization is the act of bringing the image to the screen of the mind and the imagination and visualization are generally taken as synonyms (Kotsopoulos \& Cordy, 2009). The information processing theory said that the visual representation of knowledge generally talks about mental imagery (Solso et al., 2008). In other words, mental imagery (imagination) can be seen through a visual representation of knowledge.

To collect the data, we use problem sheet, recording and interview. The collected data in this research is in descriptive data (verbal data) then analyzed in inductive way. The collected data analyzed using qualitative analysis technique (it includes interactive analysis technique model) improved by Cresswell (2014) which included reducing the data, presenting the data and making conclusion. To decide the accuration of data, the researchers do triangulation method (compare the data by student think aloud result, problem sheet, field note and interview).

\section{Result \& Discussion}

Below are descriptions of each subject in solving the problem. To concise the writing each subject were written as $\mathrm{S} 1, \mathrm{~S} 2$ and $\mathrm{S} 3$. $\mathrm{S} 1$ is as subject 1, $\mathrm{S} 2$ as subject 2, $\mathrm{S} 3$ as subject 3 and $\mathrm{P}$ as a researcher.

\subsection{Analysis of Mathematical Imagination Stage inn Subject 1 (S1)}

S1 started to work on the problems with reading the question and think aloud for 80 seconds. S1 then moving the fingers over the matter, it indicates subject tried to examine and understand the question. This activity lasted for 120 seconds, but subject has not been able to understand the question. It is seen S1 repeats to reading the question for getting the information, corresponding the statement of following the subject.

S1 : The length is not known.

Subjects were informed that the length of each square on the matter is not known. From this information then S1 see images more carefully in order to obtain the information:

S1 : The length of four small square sides is equal to the length of three large square sides. 
Subjects can know that the length of four small square sides is equal to the length of three large square sides by drawing square contained in the matter. It shows S1 has been able to understand the intent of the question.

Furthermore S1 trying to find the solution of the problem. S1 moving the fingers on the table, it shows subject uses his thinking process to find the solution of the problem. This activity lasted for 70 seconds, and then subject says:

\section{S1: The length of all is 12 .}

The subject inferred the length side of all squares is $12 \mathrm{~cm}$. Although the subject can determine the length side of all squares are $12 \mathrm{~cm}$, but the subject looks still difficulty in determining the length side of each square. After contemplate a moment, subjects have perception that the length side of small square is $3 \mathrm{~cm}$ and large square is 4 $\mathrm{cm}$. This is consistent with statement of subject:

\section{S1: The length of small square is $3 \mathrm{~cm}$ and large square is $4 \mathrm{~cm}$.}

This idea emerges on based subject perception after received stimulus of the problem in question. Stimulus is the order in the matter to determine the length side of each square that fill the image. These stimuli are arising to subject perception which then emergence the idea to determine the length of each side of square. Van Alphen (2011) said that imagination appears from perception through the senses. This idea is a form of students' mathematical imagination in facing of such problems or so-called sensory mathematical imagination. Wibowo and As'ari (2014) said, sensory mathematical imagination can be seen through the emergence of students' perceptions due to stimulus of the problem. This is reinforced by the answers of subject that demonstrates this.

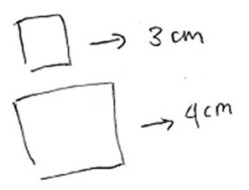

Figure 1. S1's drawing of square with the length

As confirmed why subject determines the length side of small square is $3 \mathrm{~cm}$ and large square is $4 \mathrm{~cm}$, subject is not able to disclose the reason. This reinforces the notion that sensory mathematical imagination is closely linked to perception of student. The basic of sensory imagination is perception, such as the experience of presence a stimulus (Currie and Ravenscroft, 2002). It is reinforcement by Ferrara (2006), said imagination in mathematics learning is as student motoric and perception main activity. To reinforce this case, the researcher conducted a interview with subject:

$\mathrm{P} \quad$ : Why is $3 \mathrm{~cm}$ and $4 \mathrm{~cm}$, instead of $3 \mathrm{~cm}$ and $5 \mathrm{~cm}$ ?

S1 : Silent.

Subject is not able to disclose the reasons of choosing the length side of square is $3 \mathrm{~cm}$ and $4 \mathrm{~cm}$ not others. This indicates that the subject's perception determines the length side of square $3 \mathrm{~cm}$ and $4 \mathrm{~cm}$ by looking at the relationship between the total length $(12 \mathrm{~cm})$ with the length of each square.

Description in above shows $\mathrm{S} 1$ is able to appear a sensory mathematical imagination in solving the problem, but can not appear another type of mathematical imagination. Structure of sensory mathematical imagination process of $\mathrm{S} 1$ can be illustrated in the diagram below. 


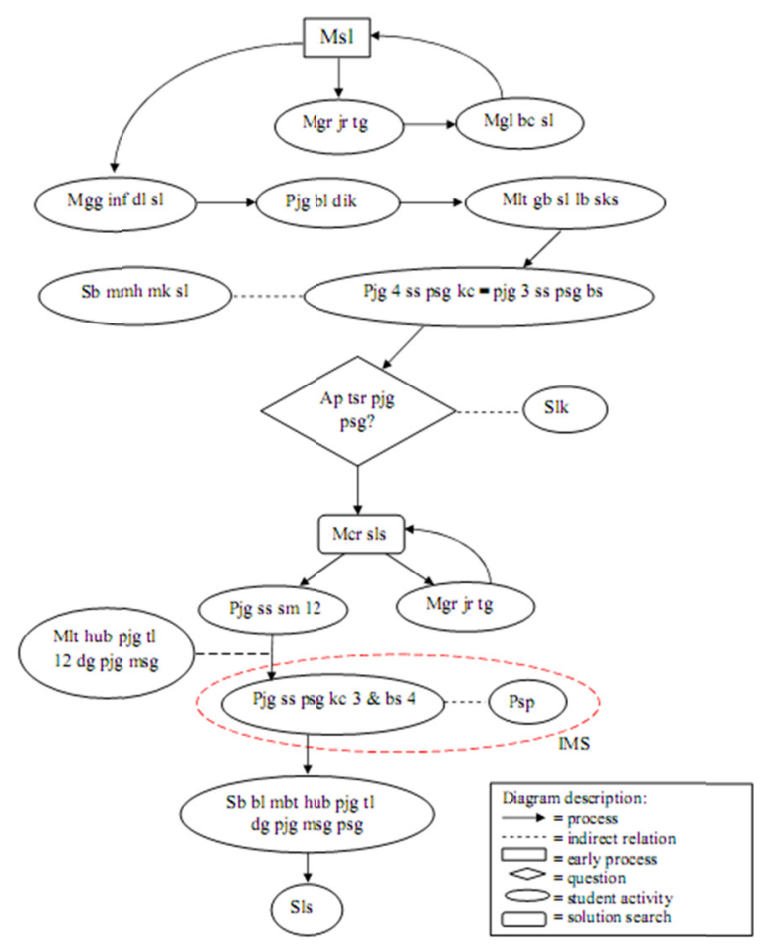

Diagram 1. S1's process of sensory mathematical imagination

Table 1. S1's term code process of mathematical imagination

\begin{tabular}{ll}
\hline Term & Code \\
\hline Problem & Msl \\
\hline Moving the fingers & Mgr jr tg \\
\hline Repeating reading the matter & Mgl bc sl \\
\hline Digging information in the question & Mgg inf dl sl \\
\hline The length is unknown & Pjg bl dik \\
\hline Seeing pictures of the matter more carefully & Mlt gb sl lb sks \\
\hline Length of 4 sides of small square = length of 3 sides of large square & Pjg 4 ss psg kc $=$ pjg 3 ss psg bs \\
\hline Subject able to understand of intent the matter & Sb mmh mk sl \\
\hline Do up the length of square sir? & Ap tsr pjg psg? \\
\hline Please & Slk \\
\hline Finding solutions & Mcr sls \\
\hline Moving the finger & Mgr jr tg \\
\hline The length side of all 12 & Pjg ss sm 12 \\
\hline Seeing relationship between the total length $(12 \mathrm{~cm})$ with the length of each square & Mlt hub pjg tl 12 dg pjg msg psg \\
\hline The length side of small square is $3 \mathrm{~cm}$ and large square is $4 \mathrm{~cm}$ & Pjg ss psg kc $3 \&$ bs 4 \\
\hline Perception & Psp \\
\hline Sensory mathematical imagination & IMS \\
\hline Subject has not been able to make a more distant relationship between the total length with the length of & Sb bl mbt hub pjg tl dg pjg msg \\
each square & psg \\
\hline Finished & Sls \\
\hline
\end{tabular}

\subsection{Analysis of Mathematical Imagination Stage in Subject 2 (S2)}

S2 begins working on the problems by reading and thinking aloud for 90 seconds. S2 repeats reading the matter to understand the problem by pointing the fingers at the problem lasted for 150 seconds. Then S2 said, "There are three large squares and four small squares". Based on the picture on the matter, subject can mention that there are three of small squares and four of large squares. Then subject draws it on the answer sheet as shown below: 


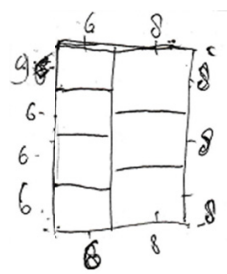

Figure 2. S2's draw beginning square

Subject moves his fingers to trace square image and decides the length of small square is 5 unit, so the length of all squares is 20 unit. Number that can be crossed beside number 9 is number 5 (Figure 2 above). This idea is a subject perception that appears due to stimulus of the problems that can be regarded as a form of sensory mathematical imagination.

Then subject said, "the total of right side and left side is equal represented 20: 3". Subject analyzes the total length of left square side and right square side is equal, so the length of one square in the right side is 20:3. But it is becoming cognitive disagreement on subject, because the result is in decimal form. To further simplify, subject finds another idea that the solution is not in decimal form.

Subject decides the length of small square is 6 unit, so that the total length of small square is 24 unit. This length is equal to the total length of large square, the result of the length of each large square is 8 unit derived from 24 : 3. Subject concludes that the length of each side of large square is 8 unit and 6 unit for small square. It the representation of subject can be seen below:

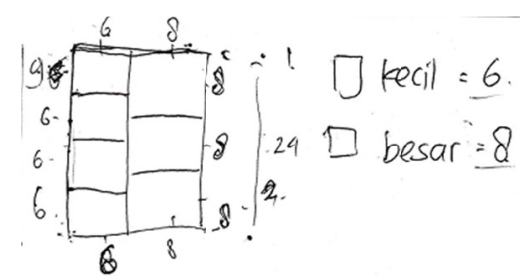

Figure 3. Deciding of Small and Large Square Do S2

From above, subject is able to appear relevant ideas in solving the problem which is a form of creative mathematical imagination. Wibowo and As'ari (2014) said creative mathematical imagination can be seen through appears of relevant or irrelevant ideas in solving mathematical problems. Imagination of this type appears as a form of student creativity in solving the problems. Creative imagination is the emergence of ideas with unexpected ways in solving problems (Currie \& Ravenscroft, 2002). Egan (2005) said that, through the imagination the students can make more extensive and creative in their thinking way. Appearing of creative mathematical imagination through divergent thinking was by subject. This opinion is same as Saiber and Turner (2009), it said divergent thinking can influence the subject imagination ability.

After finding the length of square side is 6 unit and 8 unit, subject draws square as the matter by decided that the side length of small square is 9 unit. Thus obtained the total length of small square is 36 unit, the length equals with the total length of large square. Retrieved the length of one side of large square is $36: 3$, which is 12 unit. The representation of subject can be seen below:

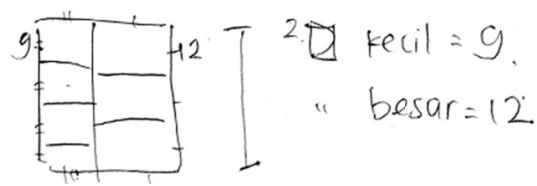

Figure 4. S2's deciding of other side the length

This idea is the previous step, which can still be categorized as creative mathematical imagination of students in solving the problem. Subject was able to find another number to fill the length side of square that corresponding 
to the picture. But this has not filled what is referred to in a matter to find the side length of square as much as possible in order to fill the image.

Subject still have trouble to find how many is possible square length that fill the image. It is accordance with what is disclosed by subject:

$\mathrm{P} \quad$ : How many is possible square length?

S2 : I do not know sir.

From the above, subject has already been able to find several pairs of the length sides of small square and large square, but subject is still difficulty in generalizing the solutions. In this case subject can produce sensory and creative mathematical imagination to solving the problems. Subject has not been able to issue another mathematical imagination in solving this problem. The structure of sensory and creative mathematical imagination of subject can be illustrated in the diagram below.

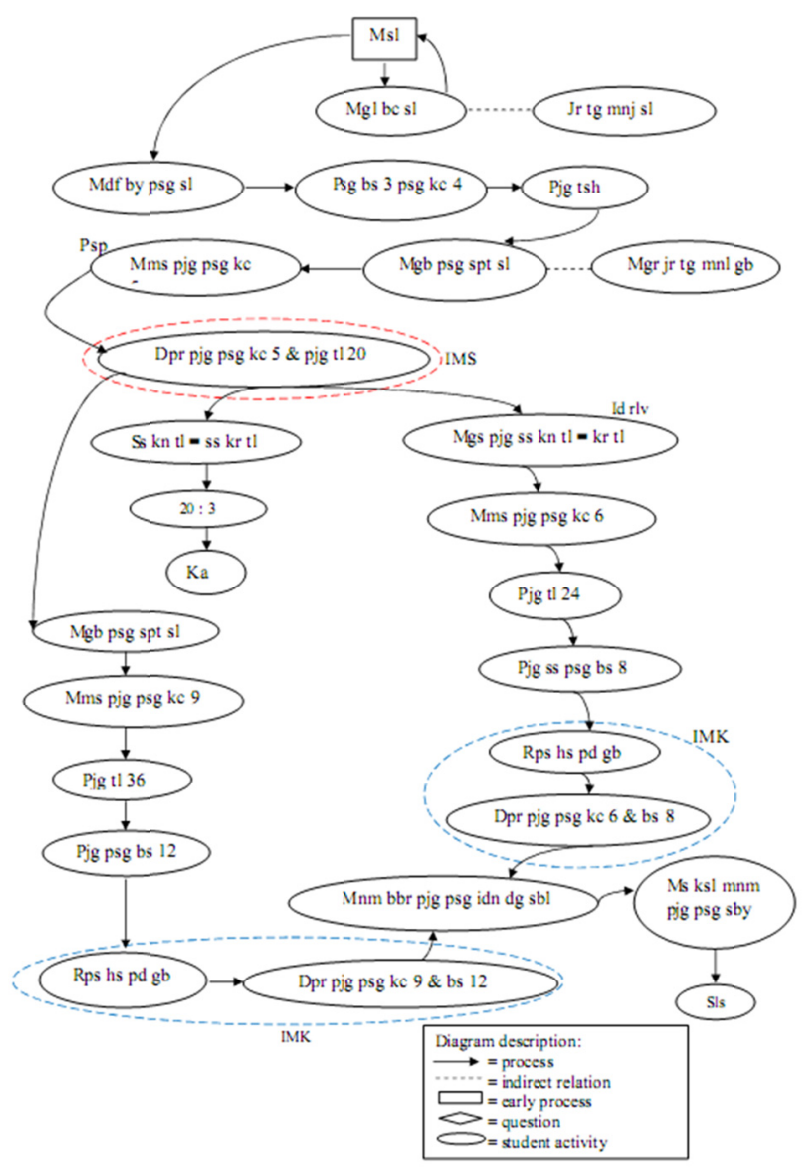

Diagram 2. S2's process appear of sensory and creative mathematical imagination

Table 2. S2's term code of mathematical imagination process

\begin{tabular}{ll}
\hline Term & Code \\
\hline Problem & Msl \\
\hline Repeat reading the matter & Mgl bc sl \\
\hline Fingers point to the problem & Jr tg mnj sl \\
\hline Identifying a square lot in question & Mdf by psg sl \\
\hline There are 3 large squares, there are 4 small square & Psg bs 3 psg kc 4 \\
\hline Its length is up & Pjg tsh \\
\hline Draw a square as in the problem & Mgb psg spt sl \\
\hline Moving the fingers trace for images & Mgr jr tg mnl gb \\
\hline
\end{tabular}




\begin{tabular}{ll}
\hline Deciding a small square length is 5 units & Mms pjg psg kc 5 \\
\hline Perception & Psp \\
\hline Obtained a small square length is 5 units and total length is 20 units & Dpr pjg psg kc 5 \& pjg tl 20 \\
\hline Sensory mathematical imagination & IMS \\
\hline Total right side = total left side & Ss kn tl = ss kr tl \\
\hline Comma & Ka \\
\hline Draw a square as the matter & Mgb psg spt sl \\
\hline Deciding a small square length is 9 units & Mms pjg psg kc 9 \\
\hline Total length is 36 units & Pjg tl 36 \\
\hline Large square length is 12 units & Pjg psg bs 12 \\
\hline Results Representation in the image & Rps hs pd gb \\
\hline Retrieved the length of small square is 9 units and large square is 12 units & Dpr pjg psg kc 9 \& bs 12 \\
\hline Analyzing total length of right side = left side & Mgs pjg ss kn tl = kr tl \\
\hline Relevant ideas & Id rlv \\
\hline Deciding a small square length is 6 units & Mms pjg psg kc 6 \\
\hline Total length is 24 units & Pjg tl 24 \\
\hline The length of large square side is 8 units & Pjg ss psg bs 8 \\
\hline Result Representation in the image & Rps hs pd gb \\
\hline Obtained the length of small square is 6 units and large square is 8 units & Dpr pjg psg kc 6 \& bs 8 \\
\hline Creative mathematical imagination & IMK \\
\hline Finding a few square length that is identical to the previous & Mnm bbr pjg psg idn dg sbl \\
\hline Still having trouble to find square length as much as possible & Ms ksl mnm pjg psg sby \\
\hline Finished & Sls \\
\hline & \\
\hline
\end{tabular}

\subsection{Analysis of Mathematical Imagination Stage in Subject 3 (S3)}

S3 begin working on the problems by reading and thinking aloud for 70 seconds. S3 reiterated "there are four congruent squares and three congruent squares anyway", then repeats reading the matter to understand the intent of the question. "Find the possible side length of each square" subject said quietly. Subject is still trying to understand the intent of the question. Subject then mutters "congruent?", then subject repeats the phrase "find the possible side length".

After a few moments, subject draws a square and calculates how many square in the problem. But subject re-reads the questions and repeated them several times. This indicates subject is still trying to understand the intent of the question. Subject then decided all the width of the image in question is $10 \mathrm{~cm}$ and all the length is $12 \mathrm{~cm}$. This is the evident from the representation of this subject.

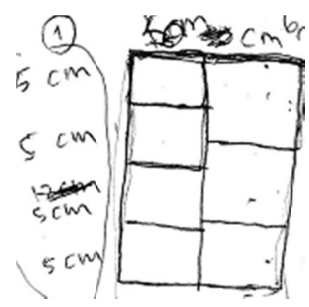

Figure 5. S3's beginnings perception that doing

This representation is a form of sensory mathematical imagination on the subject. These imaginations appear with stimulus of the problems that inflicts to the perception of subject on side length of total square and width square. Shown in the picture above that $10 \mathrm{~cm}$ and $12 \mathrm{~cm}$ was made by subject, and then the subject crossed out it. After deciding the total length and width of square, subject searches a length for each square with the outlines from the total of length and width. But subject is still trouble to find the length of square side to be equal.

Subject knows that the steps are less precise, so that subject crossed number $10 \mathrm{~cm}$ and $12 \mathrm{~cm}$ on the answer (see Figure 5 above) and replace it by other number. The method of deciding the side length of small square is $5 \mathrm{~cm}$ in order to obtain a total side length of small square is $20 \mathrm{~cm}$. Means that the length side of large square is 20:3 
to obtain the equal length, so that the length side of large square is $6.67 \mathrm{~cm}$. This is evident from the representation of the subject.

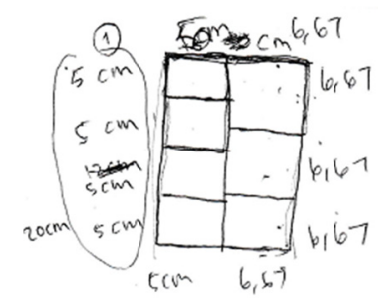

Figure 6. S3's finding the length side of square

This representation is a form of students' creative mathematical imagination. Imagination is associated with appearing of relevant ideas that can help in solving the problem (Wibowo \& As'ari, 2014). Relevant idea here is the appearing of the length side of small square $5 \mathrm{~cm}$ in order to obtain a total length of square $20 \mathrm{~cm}$. Thus obtained the length side of small square is $5 \mathrm{~cm}$ and large square is $6.67 \mathrm{~cm}$.

"The results are much?" the authors said. "No" replied subject, then subject is reading the matter again to confirm the order of the question. Subject seeks solutions again to fill the length side of how many square that fill images in the matter. Subject then said "the length side multiplied by two", that is $5 \mathrm{~cm} \times 2=10 \mathrm{~cm}$ and 6.67 $\mathrm{cm}$ x $2=13.34 \mathrm{~cm}$. Representations were made by subject looks like the image below.

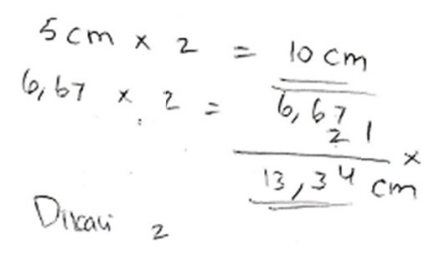

Figure 7. S3's finding the length other side

Subject can find another solution that fills these images $(10 \mathrm{~cm}$ and $13.34 \mathrm{~cm})$. However, this solution does not say that it fills the length side of square as much as possible. When the author asked "can you find as much as possible?", subject argues "the important one is the length side multiplied by 2 , multiplied by 2 , and so on". This idea appears based on the student's previous experience in solving the problem. The experience makes the student enriches a perception, so it build imaginative image (Van Alphen, 2011). In Figure 7 above subject write "multiplied by 2 and so on", this representation is a form of recreative mathematical imagination of student. Subject is able to generalize the solution by double size the length of each side, and then it will obtain the new length for each side. When the subject is able to generalize it is a form of recreative mathematical imagination produced by the students (Wibowo \& As'ari, 2014). Currie \& Ravenscroft (2002) says, recreative imagination is the ability to construct ideas from different perspectives of an experience. Generalization is obtained based on previous student experience in solving the problem. Generalization is built by subject through various perspectives resulting in a general form that fill the solution.

From the description above, S3 is capable to produce sensory, creative and recreative mathematical imagination to solving the problem. The structure process of sensory, creative and recreative mathematical imagination of S3 can be illustrated in the diagram below. 


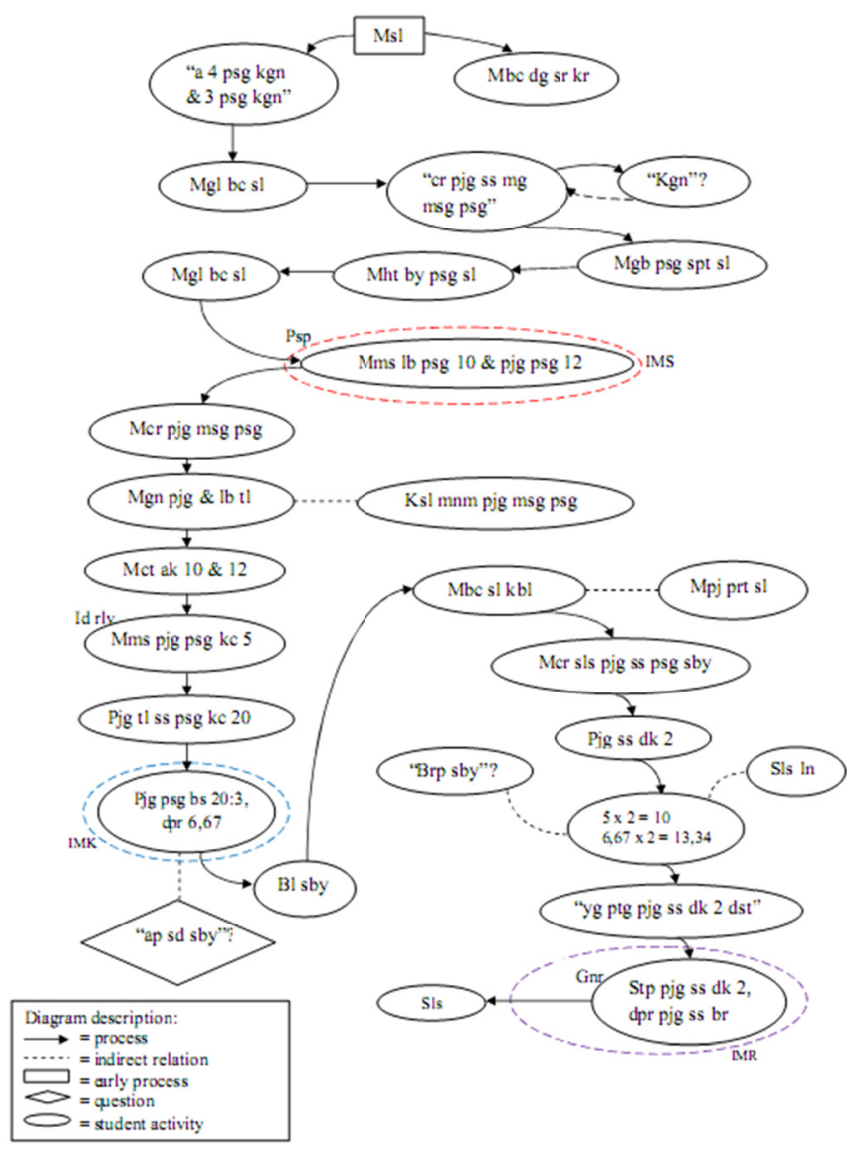

Diagram 3. S3's process of sensory, creative and recreative mathematical imagination

Table 3. S3's term code process of mathematical imagination

\begin{tabular}{ll}
\hline Term & Code \\
\hline Problem & Msl \\
\hline Reading with think aloud & Mbc dg sr kr \\
\hline "there are four congruent squares \& three congruent squares " & "a 4 psg kgn \& 3 psg kgn" \\
\hline Repeat reading the matter & Mgl bc sl \\
\hline "Find possible side the length of each square" & "cr pjg ss mg msg psg" \\
\hline "congruent" & "Kgn" \\
\hline Draw a square as in the problem & Mgb psg spt sl \\
\hline Count the number of square on the matter & Mht by psg sl \\
\hline Repeat reading the matter & Mgl bc sl \\
\hline Deciding wide of all square is $10 \mathrm{~cm}$ and length of all square is 12 cm & Mms lb psg 10 \& pjg psg 12 \\
\hline Perception & Psp \\
\hline Sensory mathematical imagination & IMS \\
\hline Looking the length of each square & Mcr pjg msg psg \\
\hline Elaborating on the length and width of its total & Mgn pjg \& lb tl \\
\hline Difficulty in finding the length of each square & Ksl mnm pjg msg psg \\
\hline Cross out number 10 cm and $12 \mathrm{~cm}$ & Mct ak 10 \& 12 \\
\hline Deciding the length of small square is $5 \mathrm{~cm}$ & Mms pjg psg kc 5 \\
\hline Relevant ideas & Id rlv \\
\hline The total length of small square is $20 \mathrm{~cm}$ & Pjg tl ss psg kc 20 \\
\hline The length of large square $20: 3$, gained $6.67 \mathrm{~cm}$ & Pjg psg bs 20:3, dpr 6,67 \\
\hline Creative mathematical imagination & IMK \\
\hline "is it that much" & "ap sd sby" \\
\hline
\end{tabular}




\begin{tabular}{ll}
\hline Not as many as that & Bl sby \\
\hline Reading the matter again & Mbc sl kbl \\
\hline Clarifying the command in the matter & Mpj prt sl \\
\hline Finding solutions of the length side of square as much as possible & Mcr sls pjg ss psg sby \\
\hline The Length side multiplied by 2 & Pjg ss dk 2 \\
\hline $5 \mathrm{~cm} \times 2=10 \mathrm{~cm}$ & 5 x $2=10$ \\
$6,67 \mathrm{~cm} \times 2=13,34 \mathrm{~cm}$ & 6,67 x $2=13,34$ \\
\hline Another solutions & Sls ln \\
\hline "How often?" & "Brp sby" \\
\hline "the important one is the length side multiplied by 2, multiplied by 2 and so on" & "yg ptg pjg ss dk 2 dst" \\
\hline Each of length side multiplied by 2, so it acquired the new length & Stp pjg ss dk 2, dpr pjg ss br \\
\hline Generalization & Gnr \\
\hline Recreative mathematical imagination & IMR \\
\hline Finished & Sls \\
\hline
\end{tabular}

The description in above indicates that the stage of students mathematical imagination in solving mathematical problem consist of, the first is one stage of mathematical imagination, the second is two stage of mathematical imagination, and the third is three stage of mathematical imagination. S1 can show sensory mathematical imagination, but has not been able to show creative and recreative mathematical imagination. It can be said S1 only through one stage of mathematical imagination. Students who can show creative mathematical imagination, they would show sensory mathematical imagination first. S2 is able to show creative mathematical imagination by issuing sensory mathematical imagination first, but $\mathrm{S} 2$ has not been able to appear recreative mathematical imagination. S2 through two stages of mathematical imagination in solving mathematical problem, they are sensory and creative mathematical imagination. Similarly, students who can show recreative mathematical imagination, they should show sensory and creative mathematical imagination first. S3 can show recreative mathematical imagination by issuing sensory and creative mathematical imagination first. S3 through three stages of mathematical imagination in solving mathematical problem, they are sensory, creative and recreative mathematical imagination.

\section{Conclusion}

From the description in above, it can be concluded that the stage of mathematical imagination which through the students in solving mathematical problems proceeded with showing sensory mathematical imagination (first stage), then creative mathematical imagination (second stage) and then recreative mathematical imagination (third stage). S1 is only through one stage of mathematical imagination in solving mathematical problems, which is sensory mathematical imagination stage. S2 can be through two stages of mathematical imagination in solving mathematical problems, they are sensory mathematical imagination and creative mathematical imagination. Students who can show creative mathematical imagination (second stage), they would show sensory mathematical imagination first (first stage). While S3 can be through three stages of mathematical imagination in solving mathematical problems, sensory mathematical imagination at first, then creative mathematical imagination, and recreative mathematical imagination in the end. Students who can show recreative mathematical imagination, they would show sensory and creative mathematical imagination first. But it does not work on other way, students can show sensory mathematical imagination but they can not necessarily issue a creative and recreative mathematical imagination. That's also students who can appear sensory and creative mathematical imagination, but they can not necessarily issue a recreative mathematical imagination.

\section{Acknowledgments}

We thank the many colleagues who have given advice on this paper. We appreciate to educational institution Logaritma Junior High School, the teachers and students who helped in this study. We also thank a few people who have read and make suggestions for this paper.

\section{References}

Abrahamson, D. (2006). The Three M's: Imagination, Embodiment, and Mathematics. Paper presented at the annual meeting of the Jean Piaget Society, June, 2006, Baltimore, MD.

Carroll, M., Goldman, S., Britos, L., Koh, J., Adam, R., \& Hornstein, M. (2010). Destination, Imagination and the Fires Within: Design Thinking in a Middle School Classroom. International Journal of Art \& Design Education, 29(1), 37-53. https://doi.org/10.1111/j.1476-8070.2010.01632.x 
Chapman, O. (2008). Imagination as a Tool in Mathematics Teacher Education. Journal Mathematics Teacher Education, 11, 83-88. https://doi.org/10.1007/s10857-008-9074-z

Creswell, J. W. (2014). Research Design: Qualitative, Quantitative and Mixed Methods Approaches. California: Saga Publication.

Currie, G., \& Ravenscroft, I. (2002). Recreative Minds: Imagination in Philosophy and Psychology. Oxford: Oxford University Press. https://doi.org/10.1093/acprof:oso/9780198238089.001.0001

Egan, K. (2005). An imaginative approach to teaching. San Francisco: Jossey-Bass.

Ferrara, F. (2006). Remembering and Imagining: Moving back and forth between motion and its representation. Proceedings of the Thirtieth Conference of the International Group for the Psychology of Mathematics Education (Vol. 3, pp. 65-72). Prague: Charles University.

Kotsopoulos, D., \& Cordy, M. (2009). Investigating Imagination as a Cognitive Space for Learning Mathematics. Educ Stud Math, 70, 259-274. https://doi.org/10.1007/s10649-008-9154-0

Moleong, L. J. (2004). Metode Penelitian Kualitatif Cetakan Kelima. Bandung: Remaja Rosda Karya.

Nemirovsky, R., \& Ferrara, F. (2008). Mathematical Imagination and Embodied Cognition. Journal Educational Studies in Mathematics, 70, 159-174. https://doi.org/10.1007/s10649-008-9150-4

Saiber, A., \& Turner, H. S. (2009). Mathematics and the Imagination: A Brief Introduction. Journal of Configurations, 17, 1-18.

Samli, A. C. (2011). From Imagination to Creativity. From Imagination to Innovation: New Product Development for Quality of Life. https://doi.org/10.1007/978-1-4614-0854-3

Solso, R., Maclin, O., \& Maclin, M. (2008). Psikologi Kognitif Edisi Kedelapan. Jakarta: Erlangga.

Swirski, T. (2010). Unleashing the imagination in learning, teaching and assessment: Design perspectives, innovative practices and meaning making. $\mathrm{PhD}$ candidate, Macquarie University.

Van Alphen, P. (2011). Imagination as a transformative tool in primary school education. RoSE - Research on Steiner Education, 2(2).

Wibowo, T., \& As'ari, A. R. (2014). Jenis Imajinasi Matematis Siswa Dalam Pemecahan Masalah Matematika. Prosiding Seminar Nasional Pendidikan Matematika II. P4TK Matematika Yogyakarta.

Wilke, J. (2010). Using Imagination in the Math Classroom. Journal of Educational Perspectives, 39(2).

\section{Copyrights}

Copyright for this article is retained by the author(s), with first publication rights granted to the journal.

This is an open-access article distributed under the terms and conditions of the Creative Commons Attribution license (http://creativecommons.org/licenses/by/4.0/). 